\title{
Modelling microstructure evolution toward ultrafine crystallinity produced by severe plastic deformation
}

\author{
Yuri Estrin · Hyoung Seop Kim
}

Published online: 15 December 2007

(C) Springer Science+Business Media, LLC 2007

Erratum to: J Mater Sci (2007) 42:9092-9096
DOI 10.1007/s10853-006-1260-8

Due to Springer's error, the paper by Y. Estrin and H. S. Kim entitled 'Modelling microstructure evolution toward ultrafine crystallinity produced by severe plastic deformation' was published in two separate editions of $\mathbf{J}$ Mater Sci [Vol. 42(5), pp. 1512-1516, 2007 (doi 10.1007/s10853-0061282-2) and Vol. 42(21), pp. 9092-9096, 2007 (doi 10.1007/ s10853-006-1260-8)]. The second publication of this paper should be disregarded and all references should cite the first version.
The online version of the original article can be found under doi:10.1007/s10853-006-1260-8.

\section{Y. Estrin $(\square)$}

Institute of Materials Science and Technology, Clausthal

University of Technology, Agricolatrasse 6, 38678 Clausthal,

Germany

e-mail: juri.estrin@tu-clausthal.de

H. S. Kim (ه)

Department of Metallurgical Engineeering, Chungnam National

University, Daejeon 305-764, Korea

e-mail: hskim@cnu.ac.kr 